\title{
doispontos:
}

\section{Corpo e individuação: percursos espinosistas pela dança}

\author{
Cíntia Vieira da Silva \\ Doutora em filosofia pela Unicamp e professora na Universidade Federal de Ouro Preto. Autora do livro Corpo e \\ pensamento: alianças conceituais entre Deleuze e Espinosa e tradutora do livro Kafka; por uma literatura menor de \\ Gilles Deleuze e Félix Gattari. \\ cintiavs@gmail.com
}

\begin{abstract}
Resumo: O texto investiga a dança como modalidade de produção de subjetividades privilegiada para dar a ver a potência do corpo. Procura equacionar o problema da sobrevivência de um vocabulário mental para tratar daquilo que exprime com a máxima intensidade aquilo de que os corpos são capazes, a saber, os corpos dançantes. Esta pesquisa segue uma trilha espinosista, para encontrar um vocabulário inteiramente corporal para descrever a potência dos corpos na dança em termos inteiramente corporais.
\end{abstract}

Palavras-chave: Dança, corpo, mente, potência, subjetivação.

\section{Body and Individuation: Spinozian routes through dance}

Abstract: The paper investigates dance as a form of subjectivities production, which offers a privileged view on the power of the body. It seeks to equate the problem of the survival of a mental vocabulary to express the very modality in which bodies are at their upmost: dance. This research pursues an spinozian path in order to describe bodies power in dance on completely bodily terms.

Key-words: Dance, body, mind, power, subjectivation.

Com o privilégio concedido ao projeto, à concepção da obra de arte, tomados como momento separado de sua execução, não se faz jus ao papel do corpo na produção artística. Ao se dar ênfase ao papel da mente nessa produção, tomando até a linguagem como algo que apenas envolve o corpo de modo secundário, algo que inclui registro gráfico e sonoro de uma habilidade incorporal, relega-se o corpo ao papel de artífice a serviço da potência artística da mente. A proposta aqui é inverter tal perspectiva e ressaltar a potência artística do corpo mostrando em que medida a produção de arte se liga ao desenvolvimento e à descoberta de potências corporais. A produção de novas corporeidades a partir do corpo fisiológico resulta em obras de arte. As artes, por sua vez, impelem novas individuações dos corpos (dos artistas, dos fruidores, dos materiais que as compõem). Esta perspectiva que se pretende aqui explorar, ao fim e ao cabo, compreende corpo e mente como diferentes expressões de um indivíduo (ou de processos de individuação), expressões que não se distinguem de maneira substancial. A pesquisa, portanto, insere-se numa linha espinosista para investigar a dança como campo privilegiado da experimentação corporal e produção de novas corporeidades em arte.

A dança, segundo tal perspectiva, seria ocasião para que a máxima potência produtiva do corpo possa se manifestar. Produção artística, produção de corporeidades, mas também de espacialidades e temporalidades. 
O corpo que dança não se limita aos dados do corpo fisiológico assim como não se limita ao enquadramento de coordenadas espaço-temporais já estabelecidas. Cria a si mesmo e seu entorno e é modificado pelo impacto da composição com outros corpos e com toda sorte de elementos com os quais é levado a se agenciar no processo de dançar.

Lorenzo Vinciguerra defende que uma estética da produção pensada a partir de Espinosa poderia contribuir para solucionar os impasses que circundam a estética contemporânea, mantendo-a ao abrigo do relativismo que impede de definir o que é arte. Para Vinciguera,

\begin{abstract}
"o espinosismo oferece uma base de resposta, mínima talvez, mas ainda assim uma base, para o problema da essência da arte. Ela permite sustentar os dois chifres do dilema no qual se fechou o pensamento contemporâneo, aprisionado entre os defensores de uma definição nominalista (é arte tudo o que chamamos de arte) e os defensores de uma concepção realista de sua essência. Uma abordagem espinosista permite conservar estes dois aspectos ao preço de uma relativização cultural e histórica das artes, de suas hierarquias e de seus gêneros (o que, por outro lado, reflete bastante bem o estado da arte hoje em dia), mas, sobretudo, ao preço de uma refundação da estética na ética, especialmente naquilo que se poderia chamar uma ética do corpo."
\end{abstract}

Esta formulação pode dar a entender que o autor percebe a fundação da estética numa ética como um inconveniente, mas não se trata disso. Se fala em um preço a pagar, é provável que o auditório visado por esta formulação seja o dos defensores radicais da autonomia dos juízos estéticos, que poderiam ver a "refundação da estética na ética" como subordinação. No entanto, o aspecto a ser enfatizado na expressão final da citação acima não é o termo 'ética', mas o corpo. Vinciguerra insiste no enraizamento e origem corporal da produção artística segundo Espinosa:

"A cada vez que os textos fazem referências à arte e a suas obras, como é o caso no Apêndice da primeira parte da Ética, e sobretudo na Ética, III, 2, escólio, a questão essencial trata das relações entre o espírito e o corpo. No escólio, escrito como reforço do teorema que afirma que o corpo não pode determinar o espírito a pensar, nem o espírito determinar o corpo ao movimento e ao repouso, Spinoza faz mais do que em outros lugares referência às obras de arte: aedificiorum, picturarum, rerumque hujusmodi. Estas produções se fazem apenas pela arte dos homens [sola arte humana fiunt] e a causa delas deve ser buscada no Corpo Humano sem nenhuma interação com o Espírito, como o faríamos para explicar os gestos de um sonâmbulo. Tal é a via que é preciso seguir para compreender a originalidade do pensamento de Spinoza sobre a arte em sua época e talvez também na nossa. A arte é em sua essência ars corporis. Ora, enquanto expressão da potência do corpo, a essência da arte não pode ser confundida com suas propriedades miméticas. A imitação da natureza é menos a causa genética da arte que o efeito de práticas historicamente determinadas, como aquelas da pintura holandesa no tempo de Spinoza. Esta se mede a partir disso que o corpo pode fazer na medida em que ele é considerado causa adequada do que ele produz. A potência do corpo é assim a única causa adequada da arte."

A ênfase na compreensão da arte como produzida pela potência do corpo, e apenas por ela, permite esposar uma perspectiva difundida na estética contemporânea: a recusa do impulso mimético como propulsor da produção artística. Ademais, tal compreensão confere à arte um papel existencial que não passa pela questão da verdade (como gostariam os heideggerianos), mas pela afirmação e desenvolvimento da potência do corpo, o que, numa perspectiva espinosana, equivale à conquista de partes de eternidade no seio mesmo de uma existência finita:

"As artes são, portanto, as maneiras, as práticas que o corpo se esforça em pôr em obra apenas pelas leis de sua natureza e de suas técnicas a fim de aumentar sua potência e gozar assim ativamente da eternidade de sua essência. A arte do corpo propriamente falando não está no objeto, nem no sujeito, mas na maneira que tem o corpo de modificar os objetos e de ser modificado por eles no sentido de sua maior potência. A potência do corpo é assim tanto a causa adequada das obras de arte, quanto o efeito da arte que ele põe em obra. Se as artes não são eternas, mas sempre sujeitas em sua forma à história de sua prática, o que é feito com arte aumenta a saúde do corpo e faz a sua salvação, lhe permitindo gozar de sua eternidade. Nesse sentido, a arte como prática corporal constitui a virtude do corpo ativo e realiza uma forma de liberdade própria à imaginação, segundo uma necessidade interna que pertence ao corpo enquanto corpo. Cultivar a potência do corpo é aumentar a parte eterna do espírito, pois Spinoza escreve em Ética, V, 39: Quem tem um Corpo apto a um número muito grande de coisas, tem um Espírito 
cuja maior parte é eterna. Tudo permite, portanto, crer que nosso sentimento de eternidade é tanto maior quanto mais é desenvolvida uma arte da imaginação própria ao corpo, em condições de exprimir a alegria e a salvação que lhe são próprias. É por isso que não há filosofia sem arte. A arte de pensar [ars excogitandi] e a arte de imaginar como arte do corpo constituem em conjunto a arte de viver, o que Spinoza chama de ethica."3

Com relação à escolha de estudar a dança como criação de novas possibilidades do corpo, o livro de José Gil (Movimento total. O corpo e a dança) é um grande aliado. Gil também considera a dança como intensificadora das potências do corpo e cria, valendo-se sobretudo de Deleuze e Guattari, conceitos que fazem jus a essa produção. No entanto, apesar de todos os seus méritos, que não são poucos nem pequenos, o livro recai num lugar comum dos discursos em torno da dança, que é a sobreposição da mente sobre o corpo para explicar a potência produtiva deste. A meu ver, esta dificuldade frequente nos estudos em torno da dança poderia ser superada por meio da adoção de uma perspectiva espinosista a respeito da corporeidade. Gil se refere a Espinosa em seu livro, mas não mantém a coerência da concepção espinosista do corpo em seu requisito de igualdade e simultaneidade entre corpo e mente (ou de abolição de qualquer eminência de um sobre o outro).

E, no entanto, vários elementos presentes na concepção de corpo adotada por Gil poderiam levar à incorporação da perspectiva espinosista. Não apenas o caráter dinâmico, experimental desse corpo, mas também sua relação com o infinito. A temática de um infinito atual permeia todo o século XVII, conforme aprendemos com Deleuze em suas aulas sobre Espinosa, e tem uma formulação diretamente corporal ou corporificada em Espinosa. Os corpos de todos os indivíduos finitos, para Espinosa, são compostos por infinitas partes infinitamente pequenas, marcando a presença do infinito no interior do finito e limitado. A criação da possibilidade de atualizar o infinito na dança por meio do corpo é descrita por Gil em termos distintos, mas que podem se acomodar ao espinosismo. Segundo Gil, para dançar, "o bailarino esburaca o espaço comum abrindo-o até o infinito" ". A dança produz uma atualização do infinito em um espaço limitado.

Outro ponto que poderíamos aproximar de Espinosa é aquele que Gil designa, juntamente com Laban, como propulsor do movimento. Para Laban, na origem do movimento dançado está “(...) o esforço, que é uma espécie de força vital", e que "encerra já em si, quase no estado de latência, a forma do movimento que desenvolverá" ${ }^{5}$. Tal forma envolve também aspectos qualitativos e quantitativos, como a intensidade, por exemplo. Esta perspectiva pode ser tranquilamente acomodada à espinosana, na medida em que, para Espinosa, tudo o que um indivíduo produz, suas ações e seus afetos, são expressões do esforço (conatus) com que persevera em seu ser, numa palavra, de sua essência singular.

Mas como dar vazão aos movimentos produzidos por este esforço ou força vital de modo que eles ultrapassem as capacidades já dadas do corpo cotidiano em suas ações costumeiras? José Gil explica esse processo recorrendo a Merce Cunningham e o papel que confere à relação com o nada ou o silêncio em sua criação coreográfica. Nas palavras de Gil:

"Para Cunningham. O bailarino deve fazer silêncio no seu corpo. Deve suspender nele todo movimento concreto, sensorial, carnal a fim de criar o máximo de intensidade de um outro movimento, na origem da mais vasta possibilidade de criação de formas. Só o silêncio ou o vazio permite a concentração mais extrema de energia, energia não codificada" ${ }^{\text {. }}$

Esta energia impulsionará a produção de um corpo que dança num espaço a ser dançado por ele. O espaço da dança não é um meio externo ao corpo do dançarino, mas tampouco é um espaço interior subjetivo. A relação da dança com a leveza conecta-se a esse espaço que é construído no processo de dançar e que é indissociável do corpo que dança. Nas palavras de José Gil, a ausência de peso, a facilidade, são vividas pelo bailarino "ao mesmo tempo como propriedades de um móbil no espaço e como se os experimentasse 
no interior do seu corpo, como se a sua textura se tivesse tornado espaço. O espaço do corpo é o corpo tornado espaço.” É esta simbiose entre corpo e espaço na dança que a torna indissociável da leveza, como se não houvesse resistência entre o meio em que ocorre o movimento e aquele que se move. A ausência de peso se faz sentir não apenas nos saltos e movimentos aéreos, mas manifesta-se até mesmo nos gestos que exploram o solo, como o rastejar.

Contudo, a produção desse espaço em que peso se torna impulso, em que o movimento flui como pura energia, não é uma conquista definitiva, mas algo que deve ser continuamente retomado. A dança envolve um esforço contínuo para converter o peso em energia pura, uma luta do corpo contra a gravidade, condição à qual é incessantemente devolvido e da qual escapa enquanto dança por meio de um esforço perene.

Na medida em que cria um espaço sem peso, a dança elimina qualquer referente absoluto do movimento. A Terra não é mais fundamento do movimento, mas um ponto ao qual o corpo retorna por sua condição orgânica, física, mas do qual se desprende ao dançar. A dança envolve também a criação de um novo equilíbrio desprendido da terra. Para Cunningham, "o equilíbrio não depende do simples jogo de forças materiais em presença, mas da maneira como a consciência do corpo se reparte. Sem concentração, o bailarino não chegará a equilibrar o corpo” e, segundo José Gil, só se manterá em equilíbrio na medida em que a "consciência do movimento que o percorre" estiver presente. $\mathrm{O}$ equilíbrio dinâmico do corpo dançante envolve o abandono do equilíbrio estático do corpo dado.

O que me interessa pesquisar é um modo de descrever e pensar esse funcionamento extraordinário do corpo, essa modalidade de extrema presença, atividade e concentração em termos inteiramente corporais (ou, pelo menos, maximamente corporais). Por que utilizar, e José Gil está longe de ser o único a fazê-lo, todo um vocabulário mental para tratar de uma atividade que manifesta a potência do corpo por excelência, daquela dentre as belas artes em que o corpo é o grande protagonista (ao lado do teatro)? O termo concentração, apesar de comumente aplicado a uma atividade mental, pode se aplicar ao corpo, na medida em que descreve a busca de um eixo (ou vários) capaz de reunir as forças, de fazer convergir os esforços, seja do corpo, seja da mente. O que me parece desnecessário é descrever a concentração como consciência do corpo.

Chantal Jaquet vai longe na caracterização da dança como manifestação da potência artística do corpo, insistindo no seu protagonismo, mas ainda recai no uso de um termo marcadamente mental: inteligência. Parece-nos preferível falar de uma inteligência corporal do que de consciência, mas não é o bastante para encerrar a pesquisa, pois a herança mental ainda parece passível de ser abolida na interpretação do papel do corpo na dança. No caso de Jaquet, assim como no de Gil, a sobrevivência do mental parece mais terminológica do que conceitual, ainda assim, e talvez por isso mesmo, seus esforços são estímulos ao aprimoramento da expressão da primazia do corpo. Vejamos como, à exceção da inteligência, os termos com que Jaquet exprime o problema conferem ao corpo o papel principal:

"A arte coreográfica implica uma modificação das relações ordinárias entre a mente e o corpo. Em balé, com efeito, é o corpo que conduz a dança e que submete a mente às suas próprias leis. A arte coreográfica consumada implica um consentimento da inteligência que se absorve no corpo, que renuncia a deliberar, caso contrário, o dançarino hesita, perde o ritmo e dá um mau passo. A dança não tolera nenhum prazo de reflexão, ela requer uma imediaticidade do movimento cujas figuras se impõem inelutavelmente. Contrariamente à especulação que acaricia os possíveis até o dilema, a dança é uma linguagem que abole a alternativa e o debate para se inscrever sob o regime da necessidade. Certamente, ela exige pés plenos e não licencia a inteligência, mas ela convoca por assim dizer uma inteligência do corpo, mais intuitiva do que reflexiva." 
Não se trata de considerar a mente inativa no processo da dança, como bem formula Jaquet, ao falar do não licenciamento da inteligência. Segundo uma perspectiva espinosista, corpo e mente são simultaneamente ativos ou passivos, logo, se o corpo dança, manifestando sua potência criativa, a mente também se encontra em atividade. O que me parece desejável evitar é a precipitação em mesclar a mente na descrição do que ocorre com o corpo dançante e, mais grave ainda, a precipitação em atribuir o traço distintivo do corpo dançante criador do corpo cotidiano a algo mental. E não me parece satisfatório procurar caracterizar essa consciência do corpo que se cria no aprendizado da dança como distinta da reflexão. A primazia do mental se mantém, ainda que se o conceba em modelo distinto do reflexivo. Para refrear a tendência de atribuir superioridade ao mental sobre o corporal, e evitar que tal tendência iniba a pesquisa a respeito daquilo que $\mathrm{o}$ corpo produz a partir de seus próprios meios, sua própria estrutura, seu próprio funcionamento, o primeiro passo é supor que a atividade da mente é simultânea à do corpo, e não sobreposta a ela, muito menos sua causadora. Assim, é prudente evitar o vocabulário mental, e buscar tudo descrever, explicar e interpretar em termos inteiramente corporais. Depois de esgotar as possibilidades do registro corporal, ao menos segundo os recursos deste momento, pode-se investigar o que ocorre simultaneamente no âmbito mental a quem dança.

Esta é a contribuição que minha pesquisa se propõe a fazer para uma filosofia da dança. O livro de José Gil, Movimento total: o corpo e a dança, é prolífico na criação de conceitos e faz um bom apanhado da história da dança (não é um recenseamento exaustivo, mas este não é seu propósito), detendo-se longamente na análise do trabalho da figura inaugural da dança contemporânea, Merce Cunningham. Além de expandir a análise para experiências na dança não estudadas por José Gil (nem por outros estudiosos), procurando acompanhar processos de criação desenvolvidos atualmente no Brasil (sobretudo em Belo Horizonte, a pesquisa tentará ampliar a análise em termos corporais, enriquecendo o vocabulário explicativo e interpretativo calcado no corpo.

Para iniciar o trajeto de pesquisa, tomemos como ponto de partida a análise que José Gil faz do trabalho do dançarino e coreógrafo Merce Cunningham. Sua dança rompe com três princípios comuns ao balé clássico e à dança moderna (mesmo a de Martha Graham, em cuja companhia Cunningham dançou por alguns anos e fez seu aprendizado). Cunnignham considera que o movimento é expressivo em si mesmo ${ }^{10}$, de modo que rompe com o "princípio de expressão", segundo o qual os movimentos exprimem emoções. Além disso, a criação de Cunningham não mais segue os princípios "de sublimidade, que até mesmo quando se quer sublinhar a ligação do corpo com a terra (caso de Martha Graham), afirma o primado do céu e do inteligível sobre o sensível, e de "organização", princípio que concebe o "corpo do bailarino", ou o conjunto de corpos "dos bailarinos" como "um todo orgânico cujos movimentos convergem para um fim"11.

As estratégias utilizadas por Cunningham para criar em ruptura com esses princípios são o acaso e a "decomposição das sequências 'orgânicas"'12 de movimento. O acaso era utilizado como procedimento de composição, de modos diferentes, como, por exemplo, o sorteio de combinações de posições das partes do corpo, cada posição e cada parte sendo sorteada separadamente. A posição global do corpo resultante desses sorteios fragmentados causava estranheza ao próprio dançarino, além disso, a transição de uma posição a outra frequentemente colocava problemas que só poderiam ser resolvidos na experimentação corporal, por não serem transições habituais ou integrantes do repertório já codificado no balé.

Outra consequência do acaso como princípio compositivo é a disjunção entre coreografia e música. A música dos espetáculos de Cunnigham não é o referencial para a coreografia, que não se propõe a ser a dança daquela música. Cunningham convida compositores, em geral, bastante arrojados, como John Cage, por exemplo, para comporem uma peça com duração determinada e baseada em uma estrutura que já definiu e que deverá orientar também a composição da coreografia. Tal estrutura é o ponto de ligação 
entre dança e música, mas a relação entre ambas nunca é de ilustração, ou de expressão recíproca, uma nunca funcionando como referente da outra no caso dos espetáculos de Cunningham. Cada uma das composições, coreográfica e musical, faz-se em separado e se produz um encontro entre elas na apresentação do espetáculo (muitas vezes, isto era literal, e o dançarinos não tinham acesso à peça musical a não ser na apresentação, ou pouco antes. A unidade do novo indivíduo composto por música e dança não repousa numa relação de semelhança ou de interexpressividade, mas de disjunção ou diferença).

Na técnica de contato improvisação, criada por Steve Paxton, um encontro deste tipo é promovido entre corpos. Dois ou mais dançarinos se põem a dançar, improvisando juntos, sem mimetizar um ao outro e sem estabelecer diretrizes prévias ao encontro. Gil descreve tal encontro referindo-se a Espinosa: "Steve Paxton procura descrever o mecanismo mais simples de intensificação da energia quando, como diria Espinosa, dois corpos se encontram e se afetam um ao outro"13. Gil descreverá o que ocorre a corpos que dançam improvisando juntos nos termos da composição de um novo indivíduo, em estilo bastante espinosista. Contudo, Gil explica tal composição como uma "comunicação dos inconscientes ${ }^{14}$ ". Mas, se como o próprio Gil observa, e o nome da técnica, Contato Improvisação, sugere, a composição se inicia por uma "comunicação pelo tato" ${ }^{15}$, será mesmo necessário escrever em termos de um inconsciente dos corpos forjado a partir da consciência corporal? Em que medida expressões desse tipo são meramente metafóricas, aludindo a uma unidade e a uma reversibilidade entre corpo e mente, que acaba por reintroduzir a eminência do mental sobre o corporal?

Parece-me difícil sustentar a igualdade e a simultaneidade a partir de um modo de expressão semelhante a este: "a consciência do corpo é movimento do pensamento". Essa formulação metafórica não seria censurável se não culminasse numa outra que reestabelece a superioridade do mental: "é necessário que à 'direita' e à 'esquerda' sejam dimensões do pensamento para que possamos entender o que quer dizer 'virar à esquerda' 16 ". Gil postula a imanência entre corpo e pensamento, mas as fórmulas com que a exprime traem a horizontalidade entre os dois registros e reafirma o primado mental, característico do dualismo de que afirma querer escapar.

Marie Bardet, pesquisadora que se diferencia dos outros teóricos que citei por sua formação nas duas áreas na interseção das quais produz sua pesquisa (dança e filosofia), critica uma outra metáfora recorrente entre os estudiosos da dança: a imagem da leveza. Vimos que Gil insiste na ausência de peso, mas não propriamente em sentido metafórico, mas como uma modalidade de relação com o meio ou espaço. No entanto, para Bardet, esse caráter leve ou aéreo que se procura conferir à dança corre o risco precisamente de afastá-la daquilo que, segundo a perspectiva que busco adotar em minha pesquisa, constitui seu maior interesse: o fato de a dança manifestar a potência do corpo de um modo que talvez seja o ápice de sua visibilidade. Ouçamos a advertência de Bardet:

A dança para os filósofos constitui quase sempre, à primeira vista, uma imagem inspiradora da leveza como desprendimento daquilo que está, no entanto, mais intimamente ligado ao corpo em seu próprio movimento, mas que parece escapar do peso e fornecer assim uma metáfora ideal do pensamento leve, fluido e puro. ${ }^{17}$

Bardet propõe, ao contrário, um encontro entre filosofia e dança que tome esta última, na esteira de Laban, como experimentação dinâmica da variabilidade das relações possíveis entre corpos e gravidade. Assim, a filosofia iria

buscar na dança, em seus desenvolvimentos estéticos passados e presentes, assim como em sua experimentação concreta, não a metáfora de um pensamento que se abstrai do peso das condições do mundo, mas a metáfora que se opera como deslocamento ancorado na realidade, 'atravessada' por uma relação já sempre em curso da massa comprometida de meu corpo com a massa da terra ${ }^{18}$. 
Não me parece que o grande interesse da dança seja sua capacidade de metaforizar, sendo indiferente se ela irá servir de imagem do pensamento ou de imagem da relação entre os corpos e a terra. Se a dança é tão fascinante, a meu ver, é por ser manifestação, apresentação ou presentificação do que pode o corpo. A dança não alude ou faz pensar na potência do corpo, ela a coloca em ação naquele que dança e a dá a ver aos espectadores. É assim também, ou de maneira próxima a esta, que os expoentes da dança contemporânea compreendiam a dança. Já vimos que Merce Cuningham insiste na expressividade do movimento por si mesmo, sem considerá-lo como expressão de algo externo a ele. Nesse sentido, a dança é investigação em torno de questões corporais, de problemas concernentes ao movimento. È desse modo que o coreógrafo descreve a composição de Torse, que surgiu de uma investigação a respeito de como mover as pernas rapidamente, simultaneamente aos ombros. Isso exige um trabalho do movimento do tronco que não tinha paralelo na técnica clássica.

No começo, eu não sabia se ia funcionar ou não, mas continuei tentando. Torse é a primeira dança na qual realmente peguei esses elementos. E tentei usar todos eles. Usei a ideia da direção da perna em diferentes velocidades, com diferentes ritmos, em diversos tipos de sequência; o corpo em constante mudança, com ou contra as pernas. E fazendo isso também no ar, saltando e mudando a direção do torso, que é a coisa mais difícil de se fazer. Esse é que é o material de Torse. ${ }^{19}$

Não apenas em Torse, mas em todo o seu trabalho, o que orienta a criação é a pesquisa a respeito de novas possibilidades do corpo: "a questão pode ser simples para uma dança e complexa para outra, ou pode haver diversas questões. Todas as danças nascem de algo desse gênero." ${ }^{20}$ Cunningham dá ênfase ao caráter não representativo da dança: "o tema da dança é a própria dança. Ela não tem a intenção de representar outra coisa, seja ela psicológica, literária ou estética. Tem muito mais a ver com a experiência cotidiana, a vida de todos os dias, com assistir pessoas que se movem pelas ruas." ${ }^{1}$

Apesar dessa fala, Cunningham não se aprofundou tanto na exploração do movimento cotidiano e na ruptura com o virtuosismo quanto aqueles que poderíamos chamar de seus sucessores, como Trisha Brown (que dançou na companhia de Cunningham), Yvonne Rainer, Sally Banes e Steve Paxton. O movimento que sucedeu à ruptura de paradigma empreendida por Cunningham foi o de questionar o caráter institucional da dança e implementar meios estéticos de instaurar imanência entre arte e vida. Esta parece ser uma das linhas de investigação da dança atual, ao lado de pesquisas em torno da exploração de novas tecnologias. Também parece ganhar espaço a pesquisa a respeito de como fazer do corpo dançante um corpo falante ou de deixar fluir a palavra como materialidade própria também à dança.

\section{NOTAS}

1. VINCIGUERRA, Lorenzo. “Arte como ética. Por uma estética da produção. Breve reflexão spinozista.” · Viso. Cadernos de estética aplicada n. 8 jan-jun/2 010, p. 8.

2. Id., pp. 5-6.

3. Id, pp. 8-9.

4. GIL, J. Movimento total. O corpo e a dança. São Paulo, Iluminuras, 2002, p.14.

5. LABAN, Rudolf von. The mastery of movement. Mac Donald and Evans, 1960. Apud:GIL, J. Movimento total. O corpo e a dança. São Paulo, Iluminuras, 2002, p. 15.

6. GIL, J. Movimento total. O corpo e a dança. São Paulo, Iluminuras, 2002, p. 16 
7. Id., p. 18.

8. Id., p. 22.

9. JAQUET, Chantal. Le corps. Paris, PUF, 2001, p. 242. Tradução minha.

10. "Sempre tive a impressão de que o movimento em si é expressivo, independentemente de intenções de expressividade, para além da intenção". CUNNINGHAM, Merce. O dançarino e a dança. Conversas com Jacqueline Lesschaeve. Rio de Janeiro, Cobogó, 2014, p. 106. Cunningham chega a esta afirmação a partir do comentário a respeito de várias interpretações da mesma coreografia, Winterbranch, composta a partir da "ideia de corpos caindo" (Id., p. 104). Cunnigham conta que "na Suécia, disseram que o tema era o conflito racial; na Alemanha pensaram em campos de concentração; em Londres falaram em cidades bombardeadas; em Tóquio disseram que era a bomba atômica." (Id. Ibid.)

11. GIL, J. Movimento total. O corpo e a dança. São Paulo, Iluminuras, 2002, p. 28.

12. Id., p. 29.

13. Id, p. 112.

14. Id., p. 117.

15. Id., p. 116.

16. Id., p.144.

17. BARDET, Marie. A filosofia da dança. Um encontro entre dança e filosofia. São Paulo, Martins Fontes, 2014, p. 52.

18. Id., p. 58 .

19. CUNNINGHAM, Merce. Op. cit., p. 62

20. Id., p. 63.

21. Id., p. 137.

\section{REFERÊNCIAS}

BANES, Sally. Greenwich Village 1963. Avant-garde, performance e o corpo efervescente. Rio de Janeiro: Editora Rocco, 1990.

BARDET, Marie. A filosofia da dança. Um encontro entre dança e filosofia.São Paulo: Martins Fontes, 2014.

DELEUZE, Gilles. Francis Bacon: Logique de la sensation, 2 vols. Paris, Éd. de la Différence,1981.

DELEUZE, Gilles \& GUATTARI, Félix. Mil Platôs Capitalismo e Esquizofrenia. Vol. 1 a 5. Rio deJaneiro: Ed 34, 1996.

ESPINOSA. Ética. São Paulo: Edusp, 2015.

GIL, José. Movimento Total. O Corpo e a Dança. São Paulo: Iluminuras, 2005. Martins Fontes, 2006. 
GREINER, Christine. O Corpo: pistas para estudos indisciplinares. São Paulo: Anablume, 2005.

JAQUET, Chantal. Le corps. Paris, PUF, 2001.

LEITE, Ana Rita N. L Estética da experiência, corpo e democracia: uma abordagem do contato improvisação a partir das considerações filosóficas de John Dewey. Dissertação de mestrado Programa de pós-graduação em Filosofia da UFMG). Belo Horizonte, 2017.

PAXTON, Steve. Contact Quartly. Disponível em: <http://www.contactquarterly.com/cq/webtext/ resource.html> Acesso em: 28 set. 2009.

. Lisa Nelson e Steve Paxton em conversa com Helmut Ploebst para a Ballet International. 05/99. Disponível em:<http://www.facom.ufba.br/com024/contact/artigo2.html. 